\title{
AGENT-BASED MODELLING OF OFFSHORE UPSTREAM PETROLEUM LOGISTICS
}

\author{
P. ENGELSETH \& T.M. PETTERSEN \\ Department of Logistics, Molde University College, Norway.
}

\begin{abstract}
Faced with dwindling oil prices, the petroleum industry now needs to economize its operations. A case study of upstream petroleum logistics, the management of supplies to and from petroleum platforms and rigs, is used to describe current logistics and supply chain management (SCM) challenges facing these operations in Norway. The provided case narrative reveals how an integrated planning system used to co-ordinate operations is proven relatively difficult to implement and use. As alternative research approach agent-based modelling (ABM) is applied and discussed in association with actor network theory in a SCM business-functional setting to theoretically ground use of ABM as methodology. An empirically-grounded conceptual model, the first stage of ABM methodology, is created for petroleum logistics. Findings from this first stage of inquiry also suggest how and why ABM is applicable in petroleum logistics and SCM.
\end{abstract}

Keywords: actor network theory, agent-based modelling, petroleum logistics, supply chain management.

\section{THE BUSINESS CHALLENGES AND THE RESEARCH ISSUE}

Due to the fall in oil prices, the Norwegian petroleum industry must economize what is deemed too costly offshore operations. Upstream offshore petroleum logistics operations secure platform operations and are associated with risk; shutting down platform oil production has severe consequences. Keeping the platform in production continuously is therefore a core aim of petroleum logistics (PL). To secure its production the platform is continuously maintained and upgraded. Each platform has, however, a unique design. This implies that service associated with maintaining and upgrading the platform needs to be engineered. PL is modelled as a network of agents in Fig. 1.

Another platform activity, drilling is vital to secure oil production and since it implies interaction with nature it is associated with uncertainty. Other constraints include platform capacity to hold people and goods. In addition, weather impacts on transport by helicopter and platform supply vessels. Different operations cannot normally be carried out simultaneously. In cases of delays or early completion of preceding services, these following services need to be re-planned. This indicates that petroleum logistics may easily be described as a complex dynamic system (CAS). To co-ordinate different offshore platform activities, the petroleum company has developed an information technology (IT)-based integrated activity planning system that has proven challenging to use. Agent-based modelling (ABM) is proposed to develop PL a case study of petroleum logistics of an offshore production platform in North-Western Norway. A conceptual model of how networking takes place embedded in various risks to secure production on an oil platform in Norway is developed. The conceptual model provides empirically-grounded understanding of operational interdependencies as perceived by the studied network agents to found later development of a computer-based model for simulation; developing understanding on how people interact to carry out PL in a complex and dynamic network context cloaked in uncertainty. 


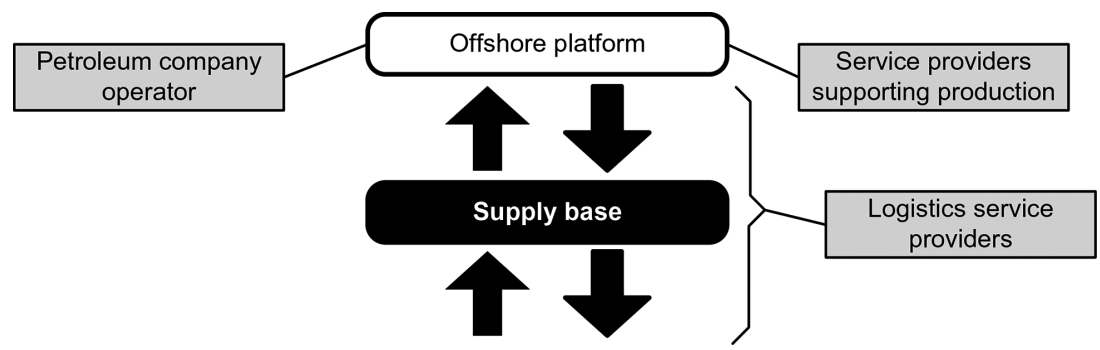

Figure 1: The petroleum logistics supply network.

\section{LITERATURE REVIEW}

The "as-is" mental business model scenario, including current economic challenges, triggers a wish to change supply operations. Surana et al. [1] state in relation to the "real world" that: "Many natural systems and increasingly many artificial systems as well, are characterized by apparently complex behaviours that arise as the result of non-linear spatio-temporal interactions among a large number of components or "subsystems". A traditional planning paradigm (mental model) will not necessarily help to improve the functioning of petroleum logistics since inherently such a system is both complex and dynamic. Loasby [2] points out with the traditional planning paradigm in mind the following: "Close attention to recipes does not ensure excellent results, and even detailed manuals often make crucial, if unconscious, assumptions about the user's skills. It is notorious that standard operating procedure, followed to the letter, produce unsatisfactory levels of performance..." A CAS is a dynamic network of many agents interacting with other agents [3]. CAS is especially fit to handle complex scenarios with a high level of uncertainty. Surana et al. [1] discern CAS, from other forms of complex systems as being systems that accommodate for human decision making; a decentralized and inherently uncontrollable system. Occurrences of coherent behaviour in the system arise from competition and cooperation among the agents within the system. In PL key types of agents are (1) oil company customer, (2) service providers to the platform, and (3) logistics service providers. Based on considerations regarding effects of micro-level decisions and resulting behaviour CAS is chosen as overall research approach [4]. According to a CAS approach, these studied systems are modelled as collections of autonomous agents, interacting with their environment and exchanging information with other agents. Such a system is not externally coordinated to produce some output; it is not driven by "plan".

CAS can be simulated using agent-based models [5]. Based on work by Boero and Squazzoni [6], Gilbert [5] discerns three levels of abstraction for agent-based models, requiring different levels of empirical validity: (1) abstract models, aiming to demonstrate theoretical properties of social processes lying behind many areas of social life; (2) middle-range models, aiming to describe characteristics of a social phenomenon sufficiently general that conclusion can be widely applied and (3) facsimile models called case-based models by Boero and Squazzoni [6], providing as exactly as possible a reproduction of a particular target system, often with the intention to make predictions of future states, consequences of institutional changes, etc.

Agent-based models have been applied to supply chains, for example, in studies aiming to control the bullwhip effect [7]. In agent-based models information can be more richly structured than just the value of a continuous real variable. This applies to both the information representation in the agents" "minds" and the information exchange with other agents to study the effects of information sharing in organisations; used to test the design and test production processes and information sys- 
tems supporting these processes [8]. Sierhuis et al. [9] describe an approach based on the "Brahms" software system to simulate human behaviour in a particular organisation structure, in which information systems can be implemented and their performance and effects can be simulated and tested under different scenarios of human action. This form of approach holds promises for the development of supply chain information systems, which are hard to test in business practice involving many actors at different stages in the supply chain. Dessalles et al. [10] discern agents implementing different levels of cognition: (1) Reactive agents, that have no cognitive rationality but only respond to environmental events; (2) Behavioural agents, that can modify their behaviours according to observed pay-offs; (3) Epistemic agents, that are aware of their behaviour and may anticipate the effects, possibly combined with social intelligence, extending the awareness to the effect of collective action. In order to interpret and use the information, agents in simulated CASs must have cognitive capabilities when ABM is used to develop petroleum logistics.

PL is embedded in supply chain management (SCM) strategy. Building on established definitions of logistics and SCM created by the Council of Supply Chain Management Professionals (CSCMP), the supply chain is modelled by Cooper et al. [11] as consisting of a set of more or less integrated business processes in a complex structure. The purpose of SCM is viewed in line with the CSCMP SCM definition; that is, as associated with integration within and between firms in a supply-oriented network context facilitating operations coordination. Cooper et al. [11] model, inspired in part by Alderson's [12] marketing channels literature, takes an end-to-end perspective focusing on the logistics of goods supply. Building on this model, Lambert et al. [13] provide, based on Cooper et al. [11], a framework for SCM implementation. This framework consists of three constructs: (1) supply chain business processes, (2) SCM components, and (3) supply network structure; applicable to ABM where agents represent the focus; processes the inputs and outputs of agent decision making, and structure as.

ABM and SCM should be grounded in social theory. Terming people in supply networks as "agents" represents social ordering [14]; to comprehend and create discourse on, for example, petroleum logistics. These patterns that this social ordering creates in networks may be considered as expression of reflexive as well as self-reflexive "modernistic" activities in a local setting where production takes place [15]. Following Fouccault [16], power relations are "...intentional but nonsubjective. If in fact they are intelligible, this is not because they are the effect of another 'instance' that explains them, but rather because they are imbued through and through with calculation: there is no power that is exercised without a series of aims an objectives..." [16]. Typical of this line of thought is: "Truth only knows and recognizes itself in a context - a context it creates for itself" [17]. Within sociology symbolic interactionism and actor network theory (ANT) provide guidance as to societally anchoring ABM to e.g. logistics systems; that context is an un-isolated complex and dynamic local form. This places focus on "...that there is ordering rather than order" [18]. A main distinction between the forerunning symbolic interactionism [19] and ANT, is that this approach includes artefacts as agents. ANT describes a form of inter-objectivity where the local setting is pertinent in understanding action, an arena for framing and summing up by human agents. Within ANT thinking Law [14] states that agents may be treated as relational effects. Second agents may be considered as ordering struggles; they are dynamic. Agency is considered as an achievement. Finally, the world is considered a set of more or less related bits and pieces having no social order. Within ANT agents may be completely or in-part non-human (artefacts); in practice what we normally consider machines with decision-making properties, as well as machines assisting people in decision-making. The agent can be a conglomerate of interacting resources; agency then rendered a process itself. This ordering is contingent, there is a layer of strategy within which reflexivity and self-reflexivity takes place. This strategy may be understood as discourse. In line with Foucault [20], reconstructions of material conditions or knowledge including exhibiting power relations in a supply 
network. Discourses convey meaning through interaction. PL viewed as "economy" includes discourse is understood as; a social pattern susceptible to change.

Within SCM Lambert et al. [13] discern between (1) physical and technical management, and (2) managerial and behavioural management. ABM brings the second aspect of SCM into focus, with physical and technical components rendered contextual. Given the inherent complexity of these technical subsystems this implies a need for engineering (designing) these systems. In this approach, however, these technicalities are rendered sub-systems. There is no vison of systemic optimizing of the PL economy. This implies need for mechanisms that listen to experiences from the "factory floor", a bottom up view of strategy-making, typically found in Lean genealogy [21]. In accordance with Hammervoll [22], economy may be viewed as comprising of two forms of complementary parts; (1) production and (2) exchange. ABM places focus on the agent and therefore on "exchange" represented by information sharing supporting production. "Production" encompasses pooling resources creating deliverables; a goods, information and services mix.

The transformation of these deliverable resources is what constitutes a market offering, what Penrose [23] terms as "service" (singular form). "Service" represents in this view appreciation that the core purpose of business is to achieve customer value. Although suppliers may be clearly aware of how this may be produced, the final test is whether customers experience satisfaction. Logistics and SCM is based on a tradition that is "goods dominant [24]. A greater degree of customer orientation is called for in order to improve the competitive standing in the marketplace. Clearly production and customer value are interrelated, and the organisation of service provision as "value co-creation" $[24,25]$ represents a gateway to improved competitive standing in the marketplace. The exchange economy can be viewed in relation to SCM; seen as embedded in management practices associated with (1) management methods, (2) power and leadership structure, (3) risk and reward structure and (4) culture and attitude [11]. These are features that are taken into consideration when applying ABM. This implies a clearly micro-level approach to these four concerns.

\section{METHOD}

The empirical evidence the conceptual modelling process rests upon is a case study of a petroleum logistics system. Following Miles and Huberman [26] and Yin [27], the case study research strategy is used when: (1) they make it possible to answer "how" and "why" research questions, (2) researchers cannot manipulate the behaviour involved during the research process and (3) researchers can seek a picture of the context the phenomenon is embedded in. A single case approach to evoke details at a micro-level [28], demanded in ABM. Taylor and Fearne [29], Fernie and Thorpe [30] and Holweg and Pil [31] state that this method is appropriate for describing actors, structure and agency relations taking place through social interaction. Research was carried out by an executive of the petroleum company described in the case. This involved mainly applying own experiences. To secure objectivity, and more in-depth understanding of management and processes a few informal semi-structured interviews were conducted. This study highlighted an ongoing quest of the petroleum producer to implement a computer-supported integrated activity planning system.

According to Croom et al. [32], the context of supply-related interaction can be described at complementary levels of analysis; as "dyads", "chain" or "network". Supply chains indicate a normative quest to integrate different firms following a linear flow of goods. Network encompasses innovation; the potential to navigate trading with different business partners as well as the feature of interacting with multiple suppliers and multiple customers simultaneously. Interaction takes place in the context of the dyad governing customer and supplier interaction [33]. Agency may accordingly be analysed in the context of (1) relationship, (2) chain or (3) network providing three distinct, but interrelated and complementary, forms of supply-related economic analysis. Supply network modelling and sim- 
ulation can benefit from the following features of agent-based models. Agent-based supply network models can be built in facsimile, furthermore, modelling of cognitive capabilities, decision making and action of agents can build on empirically validated models formulated in the social sciences. The effects of cooperation and competition in networks are simulated from the bottom up with no assumption about macro-level relations have to be made. Agent-based simulations will help to improve the understanding of the processes resulting in the behaviour and performance of supply networks as systems [34]. The explicit modelling of information exchange embedded in discourse between supply chain actors enables the application of an agent-based supply network simulation as a test-bed for supply chain information. Janssen and Ostrom [35] argue that given empirical problems with data collection and the explicit inclusion of cognitive, institutional and social processes, macrolevel statistical performance is not sufficient for validation of an agent-based model. Additional criteria are, according to Janssen and Ostrom [35]: (1) plausibility of the model, given the understanding of processes, (2) understanding why a model performs well, (3) better understanding of empirical observations gained through the model, and (4) stakeholder validation of model behaviour. A soft system modelling process is proposed by Checkland [36,37] that involves the following seven stages: (1) Entering the problem situation; (2) expressing the problem situation; (3) formulating root definitions of relevant systems; (4) building conceptual models of human activity systems; (5) comparing the models with the real world; (6) defining changes that are desirable and feasible; and (7) taking action to improve the real world situation. This analysis clarifies the purpose of modelling. Three basic criteria useful in every situation that is modelled regarding agency are: (1) efficacy which indicates, whether the transformation provides the intended outcome, (2) efficiency which indicates, whether the least possible amount of resources is being used to implement the transformation and (3) effectiveness which indicates whether the transformation helps to realize a more long-term goal. This helps to understand the root cause of a problem associated with the research topic. Fig. 2 describes this cyclic process of modelling, simulation and business process development:
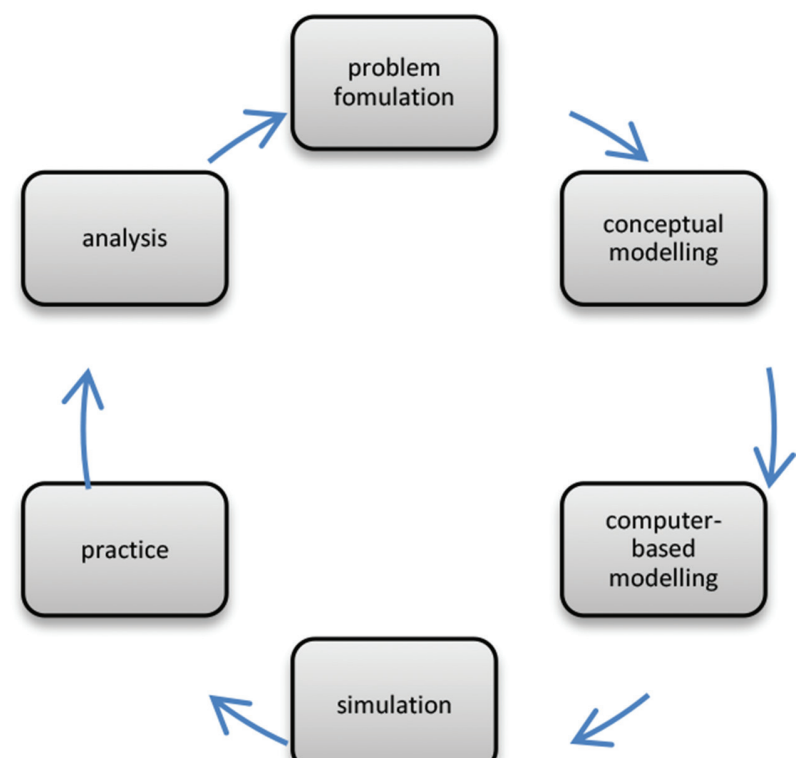

Figure 2: Agent-based modelling as a continuous cyclic development process. 
This is a form of "plan-do-check-act" circle found in "total quality management" (TQM) and widespread in lean thinking [38], developed by Shewart [39] and popularised by Deming [40]. In this study, we limit investigation to first create a conceptual model.

\section{CASE DESCRIPTION}

Annually about 20,000 tons of goods are transported mainly by sea to the platform. The supply base on land handles these goods prior to shipment. Materials have relatively long lead times demanding. In 2014, 6,800 people were transported by helicopter to and from the studied platform. Shipping includes a reverse flow of wastes and tools. It is essential that the equipment is in place when specialists arrive at the platform. The platform has a berth capacity of 130 places. There is rift about capacity use between different operators. Activities are therefore carefully coordinated with cargo deck space, helicopter capacity, berth capacity and lifeboat capacity. Another obstacle is the unruly weather. The platform is managed from the land-based headquarters of the oil company. One of the main types of activities is the maintenance and modification operations (MMO). An integrated activity planning (IAP) system is in place to manage these MMOs. AIP aims to co-ordinate plans from different actors to create common plan applying a planning frame of 90 days. While the oil company applies a 90-day plan horizon, the MMO service provider operates its own planning system with a 6-week plan horizon creating a major obstacle in information integration. The MMO service provider internally works with several plan horizons, where project plans are broken down into work packages and "plot" into the operational plan (6 week plan). This operational plan is then fed as input to the oil company's IAP.

Conflict is generated by lack of capacity. The currently used information systems do not give an accurate picture of the planned scope of activities making it challenging to accurately visualize the oil company's own activities in the network. Sharing real-time information is also difficult. The scope of work in IAP plan is visualized through the number of hours an activity is estimated to take a start and an end date. Personnel demand is not estimated which leads not considering capacity on platforms. Information exchanged uses ERP systems with different interfaces; manual operations to gather information The oil company has developed a manual Excel document entitled "Staffing Plan": a time-consuming and error prone operation. This has created an auxiliary Heli Booking sys-

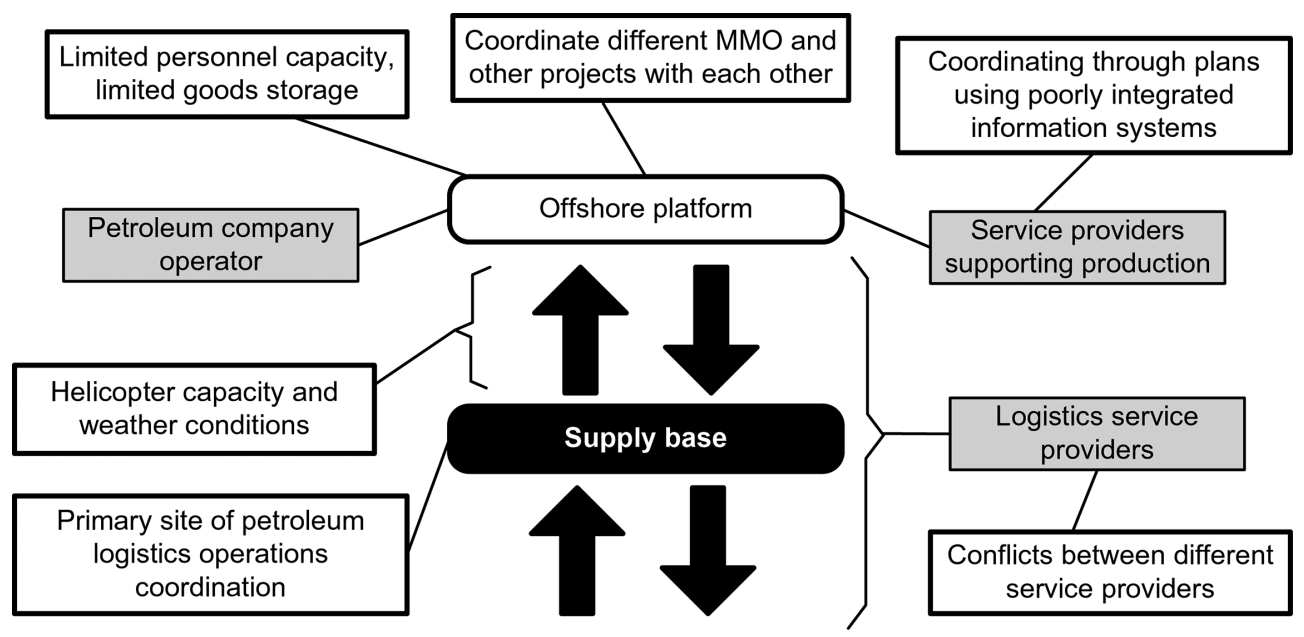

Figure 3: The preliminary conceptual model. 
tem to manage helicopter transport. In practice, sorting out conflicts due to limited helicopter capacity is a task involving revealing who is "guilty" of over-booking. The IAP plan that supports the goods flow is often overridden by the management since needed information does not reach the right decision makers on-time. It is also challenging to gather all parties to jointly plan due to various ERP systems used by different companies including variation in manual routines.

\section{MODELLING}

Modelling takes Fig. 1 as the point of departure. The conceptual model illustrated in Fig. 3 includes the business concerns described in the case narrative:

The supply base also has a key role as the site of operations, and therefore represents a node (hierarchy) when it comes to goods flow operations management, goods identification and updating information about this flow.

The case reveals complex human-machine interaction in two aspects; (1) people managing through the use of information technology software, and (2) people operating the flows of goods to and from the platform. The case description reveals how petroleum logistics involves complex network organisation embedded in a sea of uncertainty. Due to the revealed complexity and the dynamics needed to handle uncertainty, ABM should provide ample reason to apply this as development strategy. This also requires parting with the quest of planning in miniscule detail. It is proposed to develop plans that provide a guiding context. It is emphasized that the quest could be pictured as to sandwich such a plan between the petroleum logistics discourse (that is itself dynamic) and the ABM provided micro-level operational structure. This implies, in line with Fig. 2, that ABM is a dynamic enacted multiplicity; agency a form of Kaizen where established lean thinking may guide practice. Value co-creation ascends as a key feature of this proposed ABM-founded petroleum logistics development system involving an ANT-influenced "inter-objective" view of interaction; a systemic multiplicity of reality, enactment and choice. With business challenges described and discussed in light of ABM thinking founded in ANT thinking, the next step in this research is to create a computer-based ABM simulation model to initiate the Kaizen wheel of learning founded on this ontological view.

\section{CONCLUDING REMARKS}

This study is limited to investigating an initial phase of ABM; generating the conceptual model. This study provides accordingly foundation for future studies. As shown in this paper, this implies active process improvement. Most immediate is the next stage to develop a computer-based model to simulate the processes described in the conceptual model. However, given the vision to establish simulation as a Kaizen wheel of learning implies implementing simulation as a lean thinking tool [38]. This involves taking into consideration how ABM best may fit into a lean organisation applying ANT. Further research is proposed following a single case research strategy using ABM and SCM founded on ANT, also facilitating computer-based simulation.

\section{REFERENCES}

[1] Surana, A., Kumara, S., Greaves, M. \& Raghavan, U.N., Supply-chain networks: a complex adaptive systems perspective. International Journal of Production Research, 43(20), pp. 4235-4265, 2005.

[2] Loasby, B.J., The concept of capabilities. In Economic Organization, Capabilities and Coordination, Essays in Honour of G.B. Richardson, eds. N.J. Foss \& B.J. Loasby, Routledge: London, 1998. 
[3] Mitchell Waldrop, M., Complexity: The Emerging Science at the Edge of Order and Chaos, Penguin: Harmondsworth, UK, 1994.

[4] Miller, J.H. \& Page, S.E., Complex Adaptive Systems, Princeton University Press: Princeton, 2007.

[5] Gilbert, N., Agent-Based Models, London: Sage, 2007.

[6] Boero, R. \& Squazzoni, F., Does empirical embeddedness matter? methodological issues on agent-based models for analytical social science. Journal of Artificial Societies and Social Simulation, 8(4), p. 6, 2005.

[7] Moyaux, T., Chaib-draa, B. \& D'Amours, S., Information sharing as a coordination mechanism for reducing the bullwhip effect in a supply chain. IEEE Transactions on Systems, Man, and Cybernetics - part C: Applications and Reviews, 37(3), pp. 396-409, 2007.

http://dx.doi.org/10.1109/TSMCC.2006.887014

[8] Clancey, W.J., Sachs, P., Sierhuis, M. \& van Hoof, R., Brahms: simulating practice for work systems design. International Journal on Human-Computer Studies, 49(6), pp. 831-865, 1998. http://dx.doi.org/10.1006/ijhc.1998.0229

[9] Sierhuis, M., Clancey, W.J. \& van Hoof, R., Brahms: a multiagent modeling environment for simulating work processes and practices. International Journal of Simulation and Process Modelling, 3(3), pp. 134-152. 2007. http://dx.doi.org/10.1504/IJSPM.2007.015238

[10] Dessalles, J.L., Müller, J.P. \& Pahn, D., Emergence in multi-agent systems: conceptual and methodological issues. In Agent-based Modelling and Simulation in the Social and Human Sciences, eds. D. Phanpp \& F. Amblard, The Bardwell Press: Oxford, pp. 327-355, 2007.

[11] Cooper, M.C., Lambert, D.M. \& Pagh, J.D., Supply chain management: more than a new name for logistics. The International Journal of Logistics Management, 8(1). pp. 1-13, 1997. http://dx.doi.org/10.1108/09574099710805556

[12] Alderson, W., Dynamic Marketing Behavior, A Functionalist Theory of Marketing, Richard D. Irwin: Homewood IL, 1965.

[13] Lambert, D.M., Cooper, M.C. \& Pagh, J.D., Supply chain management: implementation issues and research opportunities. The International Journal of Logistics Management, 9(2), pp. 1-19, 1998. http://dx.doi.org/10.1108/09574099810805807

[14] Law, J., Organizing Modernity, Blackwell: Oxford, 1994.

[15] Giddens, A., Modernity and Self-Identity. Self and Society in the Late Modern Age, Polity Press: Cambridge, 1991.

[16] Foucault, M., The History of Sexuality: Volume 1; An Introduction, Penguin: Harmondsworth UK, pp. 94-95, 1981.

[17] Law, J., Organizing Modernity, Blackwell, Oxford, p. 106, 1994.

[18] Law, J., Organizing Modernity, Blackwell, Oxford, p. 59, 1994.

[19] Mead, G.H., Mind, Self and Society, Chicago University Press, Chicago, 1934.

[20] Foucault, M., L'Archéologie du savoir, Editions Gallimard: Paris, 1969.

[21] Holweg M., The genealogy of lean production. Journal of Operations Management, 25(2), pp. 420-437. 2007.

[22] Hammervoll, T., Service provision for co-creation of value: insights from exchange- and production economy perspectives. International Journal of Physical Distribution and Logistics Management, 44(1/2), pp. 155-168, 2014.

[23] Penrose, E., The Theory of the Growth of the Firm, Oxford University Press: Oxford, 1959. 
[24] Vargo, S.L. \& Lusch, R.F., Evolving to a new dominant logic for marketing. Journal of Marketing, 68(1), pp. 1-17, 2004.

[25] Prahaladad, C.K. \& Ramaswamy, V., Co-opting customer competence, Harvard Business Review, 78(1), pp. 79-87, 2000.

[26] Miles, M.B. \& Huberman, A.N., Qualitative Data Analysis, Sage: Thousand Oaks, CA, 1994.

[27] Yin, R.K., Case Studies Research: Design and Methods, Sage: Thousand Oaks, CA, 2009.

[28] Voss, C., Tsikriktsis, N. \& Frohlich, M., Case research in operations management. International Journal of Operations and Production Management, 22(2), pp. 195-219, 2002. http://dx.doi.org/10.1108/01443570210414329

[29] Taylor, D. \& Fearne, A., Towards a framework for improvement in the management of agrifood SCs. Supply Chain Management: An International Journal, 11(5), pp. 379-384, 2006. http://dx.doi.org/10.1108/13598540610682381

[30] Fernie, S. \& Thorpe, A., Exploring change in construction: Supply chain management. Engineering, Construction and Architectural Management, 14(4): pp. 319-333, 2007. http://dx.doi.org/10.1108/09699980710760649

[31] Holweg, M. \& Pil, F.K., Theoretical perspectives on the coordination of supply chains. Journal of Operations Management, 26(3), pp. 389-406, 2008. http://dx.doi.org/10.1016/j.jom.2007.08.003

[32] Croom, S., Romano, P. \& Giannakis, M., Supply chain management: an analytical framework for critical literature review. European Journal of Purchasing and Supply Management, 6(1), pp. 67-83, 2000. http://dx.doi.org/10.1016/S0969-7012(99)00030-1

[33] Zwick, D., Bonsu, S.K. \& Darmody, A., Putting consumers to work 'co-creation' and new marketing govern-mentality. Journal of Consumer Culture, 8(2), pp. 163-196, 2008. http://dx.doi.org/10.1177/1469540508090089

[34] Moss, S., Relevance, Realism and Rigour: A Third Way for Social and Economic Research, Manchester Metropolitan University, Centre for Policy Modelling Report: Manchester, 99(56), 1999.

[35] Janssen, M.A. \& Ostrom, E., Empirically based, agent-based models. Ecology and Society, 11(2), p. 37, 2006.

[36] Checkland, P.B., Systems Thinking, Systems Practice, Chichester, UK: John Wiley \& Sons, 1981.

[37] Checkland, P.B., Soft Systems Methodology in Action, John Wiley \& Sons: Chichester, UK, 2001.

[38] Womack, J.P. \& Jones, D.T., Lean Thinking: Banish Waste and Create Wealth for Your Corporation, Simon and Schuster: New York, 2003.

[39] Shewhart, W.A., Statistical Method from the Viewpoint of Quality Control, Dover: New York, 1939.

[40] Deming, W.E., Out of the Crisis, MIT Press: Cambridge MA, 1986. 